\section{Assessing Elementary Understanding of Multiplication Concepts}

Stephanie Z. Smith, Georgia State University

Marvin E. Smith, Georgia Southern University

Smith, S. Z., \& Smith, M. E. (2006, March). Assessing elementary understanding of multiplication concepts. School Science and Mathematics 106(3), 140-149.

Author Note: Correspondence concerning this article should be addressed to Stephanie Z. Smith, Department of Early Childhood Education, Georgia State University, P.0. Box 3978, Atlanta, GA 30302-3978.

Electronic mail may be sent via Internet to szsmith@gsu.edu

\section{Abstract}

This article summarizes the basic concepts of multiplication and provides some evidence that the traditional third-grade curriculum and instruction emphasizing memorization of multiplication facts produces much less understanding of the basic concepts of multiplication than a standards-based curriculum and instruction emphasizing construction of number sense and meaning for operations. This study also describes a collection of assessment tasks which provided meaningful evidence of children's understandings of basic multiplication concepts, including understandings of the relationships between multiplication and addition.

At the beginning of a recent school year, parents of students in the first author's third-grade mathematics class asked if their children would be following the long-standing tradition of memorizing multiplication facts. The experiences of these parents with their older children at this same elementary school had been that third grade mathematics included a heavy emphasis on memorizing facts through drill and practice, worksheets, flashcards, and other memorization aids. Timed tests had previously been used to monitor and encourage children's growing ability to recall multiplication facts. Consequently, the parents had often assisted their children in memorizing these facts. The parents knew that Dr. Smith would be continuing the standards-based curriculum she had used with their children during first and second grades as she continued her 6-year longitudinal teaching and research project. However, the parents wondered how the new curriculum's focus on problem solving, understanding, and mathematical discourse would prepare their children for the state's end-of-year examination.

About this same time, another elementary teacher told Dr. Smith about his experiences teaching mathematics in third and fourth grades. His students had mastered their multiplication tables to his satisfaction during third grade, but he was surprised how poorly they seemed to remember them the following year. When Dr. Smith mentioned this experience to the fourth-, fifth-, and sixth-grade teachers at her elementary school, they reported having had similar experiences themselves. From what these teachers said, most of their students continued to struggle with remembering multiplication facts they had memorized the previous year. This brought into question exactly what had been accomplished by these teachers' emphasis on memorizing multiplication facts during third grade. Does a curricular emphasis on memorizing multiplication facts also build understanding of multiplication concepts? 
Although much research has shown various problems with curricular overemphasis on facts and skills, O'Brien and Casey (1983a, b) specifically demonstrated that many children in grades 4-6 who have experienced a "back to basics" curriculum "do not know what multiplication is. They have algorithmic skill but no mathematical knowledge of multiplication" (1983a, p. 250). Nonetheless, many parents and teachers continue to consider memorizing basic facts as the hallmark and primary goal of school mathematics. In contrast, the Principles and Standards (National Council of Teachers of Mathematics, 2000) argued that "learning mathematics with understanding is essential" and that research shows "the alliance of factual knowledge, procedural proficiency, and conceptual understanding makes all three components usable in powerful ways" (p. 20).

These experiences and contrasting perspectives of over-emphasizing memorization of facts or developing conceptual understanding along with factual and procedural knowledge prompted us to examine the understanding of multiplication concepts along with recall of multiplication facts for two groups of students who had participated in very different learning experiences. These two groups were (a) a group of 15 third-graders from Dr. Smith's standards-based classroom immediately following their first unit on multiplication from Investigations in Number, Data, and Space (Tierney, Berle-Carman, \& Akers, 1998; commonly referred to as Investigations), and (b) a group of 10 fourth-graders at the same school who had received a traditional third-grade mathematics experience and had been "certified" by their teacher as having memorized all the traditional multiplication facts.

\section{Developing a Basic Understanding of Multiplication}

"Understand meanings of operations and how they relate to one another" is one of the Principles and Standards' three major themes for prekindergarten through Grade 12, and a host of researchers have thoroughly explored the many details of the mathematics of multiplication and how to develop conceptual understandings of it (Greer, 1992; Harel \& Confrey, 1994; Hiebert \& Behr, 1988; Sowder et al., 1998). This research indicates that although children typically develop additive reasoning quite naturally, multiplication is much more complex than addition and requires guidance to understand the new units and actions that are important elements of multiplicative situations. Focusing on the operation of multiplying two bare numbers or memorizing facts before developing an understanding of multiplicative situations and their quantities prematurely narrows students' focus and gives students the wrong impression about the need to understand what it means to multiply and the situations in which multiplying is the appropriate thing to do. In contrast to traditional direct instruction focused on memorization, number facts, computational skills, and immediate responses on timed tests, the NCTM Standards-based curriculum materials funded by the National Science Foundation emphasize sense-making activities to develop number sense, effective quantitative reasoning, and well-connected conceptual understandings. "Each level of these curricula is full of verbs such as justify, demonstrate, explain, show, confirm, defend, and so on" (Robinson, Robinson, \& Maceli, 2000, p. 116). Supported by such curricular materials, Standards-based instruction can effectively develop students' number sense, problem solving, mathematical discourse, and conceptual understanding. To be able to adequately assess and evaluate students' understandings of multiplication concepts in the context of these changes in curriculum and instruction, one needs to consider the specific details of what it means to understand multiplication and how these understandings can be easily and effectively demonstrated.

What Does It Mean to Understand Multiplication? Building an understanding of the concept of multiplication requires developing a language for thinking about and describing multiplicative situations and their quantities. Typically, children's earliest experiences with multiplication occur in situations where there are a number of groups having equal quantities. For example, if children want to know how many donuts are in four dozen, they can multiply $4 \times 12$ because they know that each of the dozens has exactly 12 donuts. Conversely, if they want to count the number of children in three classrooms, they should not multiply the number of children in one of the classrooms by three unless they are certain that each of the other two classrooms contains the same number of students.

Drawing on the mathematics education literature for a basic understanding of multiplication leads us to consider four interconnected concepts: (a) quantity, (b) multiplicative problem situations, (c) equal groups, and (d) units relevant to multiplication. Most of these understandings can develop from experiences using counting and grouping strategies to solve contextualized problems in the early grades.

Understanding quantity. The meaning of quantity often gets overlooked in addition situations, but a thorough understanding of quantity provides a 
very important foundation for understanding multiplication. A quantity is a characteristic of objects that can be counted or measured, and the value of a quantity consists of a number and a unit (Center for Research in Mathematics and Science Education, 1998). Twelve pennies is an example of a quantity — it includes both a number (12) and a unit (pennies). Number names (e.g., twelve) are often used to describe the number portion of a quantity. Other representations for the number part of a quantity include pictures (e.g., 12 circles representing 12 pennies) and the numerals 0-9 arranged in a base-10 place-value system (e.g., 12 representing twelve or 109 representing one hundred nine). In addition to the numbers in these examples, a unit must be specified to know the complete quantity. Neither the number twelve nor the numeral 12 tells what is being quantified. There could be 12 pennies or 12 suitcases of cash! Although a pictorial representation of a quantity explicitly shows one possible unit, such as 12 circles, this unit may be representing a different unit, such as 12 pennies, 12 pizzas, or 12 round cans that contain some quantity of yet another item. In each case, both the number and the particular unit must be clearly specified to completely know the quantity.

A count is a particular type of number that is part of the quantity characteristic of collections of discrete objects. It answers the question, "How many," and knowing "how many of what" provides the complete quantity characteristic. Counting is an iterative process that begins with counting by ones and progresses to skip counting using larger, equal-sized units. Students need to have sufficient experience counting collections of objects to have a strong understanding of these two aspects of quantities and the various ways of representing them. A measure (e.g., length) is a particular type of quantity that is a continuous characteristic of individual objects. Measuring is also an iterative process that includes selecting an appropriate unit of measure (e.g., an inch) and determining the number of these units representing the continuous characteristic of the object. To fully understand quantity, students need to understand the differences between discrete and continuous quantities, recognizing they use both different units (discrete vs. continuous) and different processes (counting vs. measuring) to determine the number portion of the quantity.

Understanding multiplicative problem situations. Students need to have sufficient experience figuring out the meaning of word problems describing multiplicative situations to make sense of those situations and to distinguish them from other situations suggesting addition, subtraction, or division operations. Students also need to understand the relationships between multiplication and division and be able to find each of the three possible unknown quantities in grouping/partitioning situations (e.g., given 24 cookies arranged in four bags of six cookies each, three different problems can be posed by providing any two of these three pieces of information and asking for the third). Meanings of conventional multiplication notation (e.g., $4 \times 6=24$ ) also need to be connected to the language and meanings of multiplicative situations and their units.

Understanding equal groups. Students need to have sufficient experience arranging objects into groups to understand the role of equal groups in multiplicative situations and to establish a motivation for multiplying equal groups instead of counting all of the objects in the problem. Number sense includes the ability to compose and decompose numbers. Multiplicative reasoning includes using factors and multiples as equal groups in composition and decomposition of numbers instead of using additive compositions. For example, six objects can be arranged into multiplicative groups (e.g., one group of six, two groups of three, three groups of two, or six groups of one) rather than additive groups (e.g., one and five, two and four, three and three, and six and zero). Visual images are particularly helpful in understanding grouping (e.g., the difference between a disorganized collection of 48 items and the same 48 items organized into 4 groups of 12 items or an array of 6 rows and 8 columns).

Understanding units relevant to multiplication. Students need to have sufficient experience with counting and arranging objects into groups to understand the differences between various kinds of units that are relevant to multiplication (as distinct from units that apply to additive situations), particularly the difference between singleton units (e.g., ones, donuts, or cents) and composite units (e.g., twos, fives, tens, dozens, or rows of $x$ and columns of $y$ in an $x$ by $y$ array). Students need to understand that composite units can also be counted (e.g., the number 30 is three tens as well as the counting number after 29).

Addition most often involves the joining of unequal quantities of the same unit (e.g., adding 29 cents and 54 cents). However, the two factors in multiplication most often refer to different units (e.g., multiplying 29 cats by four legs for each cat). Although adding equal quantities (e.g., 6 apples and 6 apples, which equals 12 apples) and multiplying the same units (e.g., 6 inches times 4 inches, which equals 24 square inches) are less common, it is also important for students to understand these distinctions in 
how units are involved and sometimes transformed in multiplication. When learning to write number sentences to represent these simple multiplication situations, students need to understand that one of the numbers represents the number of groups and the other represents the number in each of those groups. Unlike addition number sentences, these two numbers involve different units, which may not be explicitly indicated in the number sentence. To develop multiplicative reasoning, students need to have sufficient experience with counting, joining, and grouping processes to understand the differences involved in moving from addition to multiplication. Developing an understanding of the iterative process of multiplication can begin with skip counting or repeated addition (particularly with groups of 10), because these counting quantities themselves represent groupings that have equal numbers of the same units. Understanding the iterative process of multiplication at this informal level (number of groups and number in each group) can provide a foundation for understanding more formal definitions of the various multiplicative structures.

Given these four elements of elementary multiplication, we can begin to think about assessing students' understanding of multiplication through developmentally appropriate tasks that are able to provide evidence of understanding of these interconnected concepts.

\section{Methods}

Two small samples of students were gathered from two classrooms at one elementary school in the western U.S. We intentionally biased these samples toward the higher proficiency students (top two thirds) available in each group to reduce effects from possible outliers in the lower tail of the distributions. Ten students in the top two thirds of the traditional classroom were continuing to have a traditional experience during fourth grade. To provide a comparable group from a standards-based classroom, we identified the top two thirds (15 students) in the first author's third-grade Investigations classroom. The students in these two groups possessed similar racial, socioeconomic, and mobility characteristics.

For our assessment of children's understanding of multiplication, we started with a series of four different questions that were repeated using larger numbers (see the Appendix). This series of questions started with conventional number sentences that we expected fourth-grade children would find familiar and for which they would quickly produce correct answers. This question attended to the goal of being able to produce a correct answer, whether through recall of facts, mental computations, or counting strategies. Next we asked students to write a story problem for the number sentence to check their connections between multiplicative number sentences and problem situations, quantities, and units. These first two questions are similar to the approach taken by 0'Brien and Casey (1983a), which was based on an earlier report by McIntosh (1979).

Next in this question sequence, we asked students to draw a picture to allow us to examine their visual representations for multiplicative structures (most often shown as groupings with the same number of items in each group) and units, as distinct from those in additive relationships. (In the Investigations curriculum, students are often asked to represent their thinking in words, pictures, or numbers.) We then asked students to write an addition number sentence that showed the same thing as the given multiplication number sentence to provide additional data about students' understandings of how multiplication and addition are related.

This collection of four questions created multiple opportunities for students to make connections between what they knew and the basic multiplication concepts (quantity, problem situations, grouping, and units). Although the format of some of these questions might have been unfamiliar to students' whose curriculum consisted primarily of number facts, standard algorithms, and application word problems, this set of questions asked for a variety of representations to provide multiple opportunities to show understanding of basic multiplication concepts. The absence of any evidence of these key ideas in students' responses would provide a compelling argument that they had not yet developed the desired basic understandings of multiplication.

We followed these 16 questions with 10 word problems to provide evidence of students' understanding of various multiplication and division situations and their functional facility in solving such word problems. We designed this collection of word problems using the various multiplication and division problem types identified in research on children's mathematical thinking (see Carpenter, Fennema, Franke, Levi, \& Empson, 1999). We included multiplication, measurement division, and partitive division situations involving grouping/partitioning, rate, price, and multiplicative comparison. We used measurement division and partitive division problems in what was primarily a multiplication study to provide evidence of students' understandings of the structure and context of the problems and to illuminate careless decoding strategies that represent taking shortcuts in comprehending 
the words in the problem. The last four of these word problems used the same number combinations as the four multiplication number sentences we had given earlier in the interview (i.e., Items 1, 5, 9, and 13).

Data collected for this study included (a) students' written work created during the interview and (b) interviewer field notes about students' responses to probing questions. Probing questions included "How did you get that?" or "Can you tell me how your story problem [or picture, or number sentence] shows ?" which the interviewer asked after students responded to each interview item.

\section{Results and Discussion}

Analysis of the data involved comparing correct answers within and across the two groups of students and analyzing students' written work and verbal comments during the interviews for evidence of understanding of the basic concepts of multiplication described above.

\section{Comparing Correct Answers}

The comparative results for percent of correct answers on interview items 1-16 are shown in Table 1 for the traditional group of Grade 4 students and the standards-based group of Grade 3 students. Also shown are the percents of immediate responses to the bare number sentences (Items 1, 5, 9, and 13). We defined an immediate response as providing an answer within approximately 2 seconds of when the interviewer finished reading the number sentence aloud (which we attributed to recall), which compared to a response time longer than 2 seconds (which we attributed to a strategy other than recall of facts).

\section{Table 1}

Correct Answers by Group (Items 1-16)

\begin{tabular}{|c|c|c|c|c|}
\hline \multirow[t]{2}{*}{$\begin{array}{l}\text { Bare Number Sentences and } \\
\text { Conceptual Questions }\end{array}$} & \multicolumn{2}{|c|}{$\begin{array}{l}\text { Grade } 4 \\
\text { Traditional }\end{array}$} & \multicolumn{2}{|c|}{$\begin{array}{c}\text { Grade } 3 \\
\text { Standards-Based }\end{array}$} \\
\hline & $\begin{array}{c}\text { Immediate } \\
\text { Response }\end{array}$ & $\begin{array}{c}\% \\
\text { Correct } \\
\text { Answer }\end{array}$ & $\begin{array}{c}\% \\
\text { Immediate } \\
\text { Respoases }\end{array}$ & $\begin{array}{c}\% \\
\text { Correct } \\
\text { Answers }\end{array}$ \\
\hline $1.3 \times 4=$ & 100 & 100 & 7 & 100 \\
\hline 2. Write a story problem & & 10 & & 73 \\
\hline 3. Draw a picture & & 20 & & 100 \\
\hline 4. Write an addition number semence & & 40 & & 93 \\
\hline $5.5 \times 8=$ & 70 & 100 & 0 & 100 \\
\hline 6. Write a story problem & & 20 & & 87 \\
\hline 7. Draw a picture & & 40 & & 100 \\
\hline 8. Write an addition number sentence & & 40 & & 100 \\
\hline $9.8 \times 7=$ & 20 & 70 & 0 & 100 \\
\hline 10. Write a story problem & & 20 & & 93 \\
\hline 11. Draw a picture & & 20 & & 100 \\
\hline 12. Wrine an addition number sentence & & 30 & & 100 \\
\hline $13.9 \times 6=$ & 20 & 90 & 0 & 100 \\
\hline 14. Write a story problem & & 20 & & 100 \\
\hline 15. Draw a picture & & 20 & & 100 \\
\hline 16. Wrine an addition number sentence & & 40 & & 100 \\
\hline $\begin{array}{c}\text { Meanc Bare Number Sentences } \\
\text { (tiems 1, 5, 9, 13) }\end{array}$ & 53 & 90 & 2 & 100 \\
\hline $\begin{array}{l}\text { Mean: Conceptual Questions } \\
\text { (hems } 2 \cdot 4,6-8,10-12,14-16 \text { ) }\end{array}$ & & 27 & & 96 \\
\hline
\end{tabular}

Looking first at the results for the traditional group (Grade 4 students), we see that they immediately produced a correct answer $100 \%$ of the time only with $3 \times 4$. Only $70 \%$ of these students gave an immediate response to $5 \times 8$, and they provided fewer immediate responses and were less accurate as the products got larger $(8 \times 7$ and $9 \times 6)$, with only $20 \%$ immediate responses and $70 \%$ and $90 \%$ accuracy for the two largest products. In comparison, only $7 \%$ of the standards-based group (Grade 3 students) provided an immediate response to $3 \times 4$, and none of them gave an immediate response on the other three number sentences. However, this group was $100 \%$ accurate on all four of the bare number sentences.

The traditional group struggled with the more conceptual questions (write a story problem, draw a picture, and write an addition number sentence), and produced acceptable answers only $27 \%$ of the time. In contrast, the standardsbased group produced acceptable answers on the conceptual questions $96 \%$ of the time. Interestingly, those students in the standards-based group who initially struggled with writing a story problem or an addition number sentence early in the interview performed better as the interview progressed. Generally, students in the traditional group who did not have a useful strategy for these conceptual questions early in the interview were unable to improve their performance as the interview progressed.

Table 2 shows that the traditional students performed much better ( $84 \%$ correct) on the word problems (Items 17-26) than they did on the conceptual questions, although they still did not perform as well as the standards-based group ( $96 \%$ correct). Item 20 , a multiplicative comparison, was the only 
item where the traditional group outperformed the standards-based group (100\% versus 67\%). Some of the students in the standards-based group struggled to make sense of the difficult structure of this problem which asked them to identify the relation between two quantities where one quantity was a multiple of the other. This comparative relation is very different from the relation between a number of groups and the number of objects in each group (Carpenter et al., 1999). However, this particular multiplicative comparison structure easily fit a key word strategy.

\section{Table 2}

Correct Answers by Group (Items 17-26 and All Items)

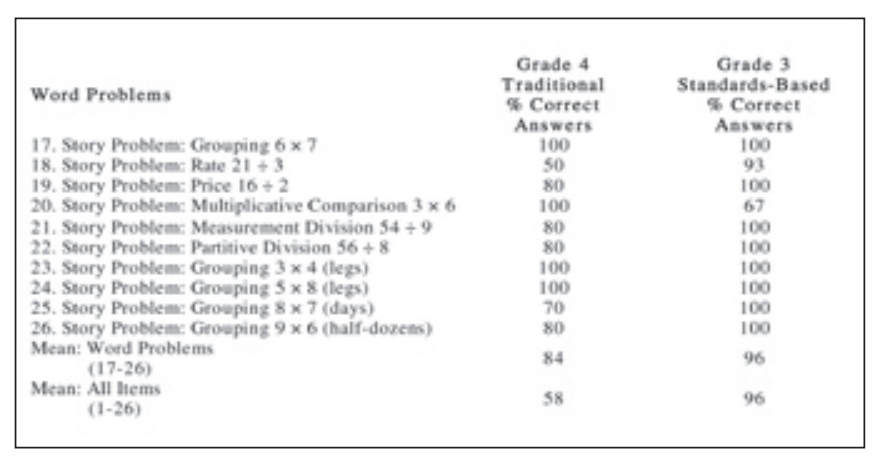

All of the traditional students recognized the word times in the problem and successfully multiplied 3 times 6 . Better evidence of understanding of multiplicative comparisons would have been provided by either the measurement division form of this problem type (e.g., The giraffe is 18 feet tall. The man is 6 feet tall. The giraffe is how many times as tall as the man?) or a partitive division form (e.g., The giraffe is 18 feet tall. She is 3 times as tall as the man. How tall is the man?).

Table 3 compares means, modes, and standard deviations across the two groups of students for the three categories of items (bare number sentences, conceptual questions, and word problems), as well as for correct answers on all items. A one-tailed $t$-test of the differences in the means for the two groups of students in each of these categories shows that the correct answers for the standards-based group were significantly higher than for the traditional group only for the conceptual questions and that this difference accounts for the significant difference in the total number of correct answers for these two groups.

\section{Table 3}

Correct Answers Statistical Comparison and t-test

\begin{tabular}{|c|c|c|c|c|}
\hline & $\begin{array}{c}4 \text { Bare } \\
\text { Number } \\
\text { Seatences }\end{array}$ & $\begin{array}{l}12 \text { Concept } \\
\text { Questions }\end{array}$ & $\begin{array}{l}10 \text { Word } \\
\text { Problems }\end{array}$ & $\begin{array}{c}\text { Total } \\
\text { Correet } \\
\text { Answers }\end{array}$ \\
\hline \multicolumn{5}{|l|}{ Traditional Group } \\
\hline Mean & 3.60 & 3.20 & 8.40 & 15.20 \\
\hline Mode & 4.00 & 0.00 & 10.00 & 7.00 \\
\hline Standard Deviation & 0.70 & 4.08 & 2.22 & 5.53 \\
\hline \multicolumn{5}{|c|}{ Standards-Based Group } \\
\hline Mean & 4.00 & 11.47 & 9.60 & 25.07 \\
\hline Mode & 4.00 & 12.00 & 10.00 & 26.00 \\
\hline $\begin{array}{l}\text { Suadard Deviation } \\
\text { f-Test Results }\end{array}$ & 0.00 & 0.92 & 0.51 & 1.10 \\
\hline Mean Diff (SB-Trad) & 0.40 & 8.27 & 1.20 & 9.87 \\
\hline tStat & 1.8091 & 6.3008 & 1.6796 & 5.5656 \\
\hline$P(T<-1)$ one-tail & 0.0519 & 0.0000 & 0.0620 & 0.0002 \\
\hline
\end{tabular}

Looking at scores and explanations for individual students, we noted that correct answers on this collection of word problems involved issues of understanding the multiplication and division situations as well as flexibility in problem solving strategies. Errors by students in the traditional group often resulted from not understanding the structure of the problem, not remembering the multiplication fact they needed, or retrieving an incorrect fact. When they could not correctly recall a particular multiplication fact, they did not attempt other, more reliable strategies for computing an answer to the problem. In particular, for Item 18 (a rate situation involving $21 \div 3$ ), their typical strategy of looking for key words and searching for an appropriate operation produced many errors.

\section{Analyzing Conceptual Questions for Evidence of Understanding}

Analyzing students' work involves looking for evidence of understanding and misconceptions in the products they produced and in their explanations of their work. This is fundamentally different from counting the number of correct answers and computing percentages. Examining details of what students produce (or what they say during conversations) provides insights into their understandings of key concepts that cannot be inferred from percentages of correct answers alone.

Writing a story problem. First, consider some examples of the ways these students responded to the request to "Write a story problem for which _ $\times$ _ is the correct number sentence." Story problems were acceptable if they described a given number of groups with a given number of items in each group, totaling to the appropriate number. 
Traditional students often wrote story problems using additive structures that had the same answer as the multiplication number sentence or simply followed its language. These typically used the same unit for both quantities, which is another indication of an additive structure. For example, traditional students wrote these story problems for $3 \times 4$ :

- "Sue had 4 candles and Tamara had 8. How many did they have in all?"

- "Bobby had 4 baseball cards. He got 3 times as many as he had already. How many did he have in all?"

One traditional student wrote a story problem that began with an additive situation, recognized this was not correct, and then specified a multiplication operation: "Josh had 3 baseball cards and his friend had 4. How many would they have if they multiplided [sic] these numbers?"

Students in the standards-based group nearly always described a grouping situation, identified a number of groups, specified a number in each group, and asked for the total number of items. For example:

- "I had 4 boxes of doughnuts. Each had 3 doughnuts. How many doughnuts do I have?"

- "I have 5 fish. Each one gets 8 pieces [sic] of fish food. How many pieces [sic] do I have to have?"

- "I have 8 boxes of toys. Each box has 7 toys in it. How many toys do I have?"

Drawing a picture. Traditional students' responses to the request to "Draw a picture that shows _ $\times$ _ " provided evidence of the same misconceptions about multiplication as their word problems: (a) multiplication is the structure of the multiplication number sentence, or (b) multiplication is the answer to a multiplication number sentence. Figure 1 shows four of these responses. Picture A shows a multiplication number sentence with a tree and grass added. Picture B shows baseballs in place of the numbers in a horizontal number sentence. Picture $\mathrm{C}$ shows stars in place of numbers in a vertical number sentence. Picture D shows the answer to $3 \times 4$ as 12 cubes without any grouping of the cubes.

\section{Figure 1}

Pictures by Grade 4 Students in the Traditional Group



Figure 2 shows four examples that are typical of pictures by students in the standards-based group. Picture E shows five fish in a fish bowl, with each fish having eight pieces of fish food. Picture F shows 12 donuts arranged in three boxes of four donuts each. Picture $G$ shows eight boxes labeled as having seven items in each box. Picture H shows 56 squares arranged in an array of eight rows and seven columns.

\section{Figure 2}

Pictures by Grade 3 Students in the Standards-Based Group

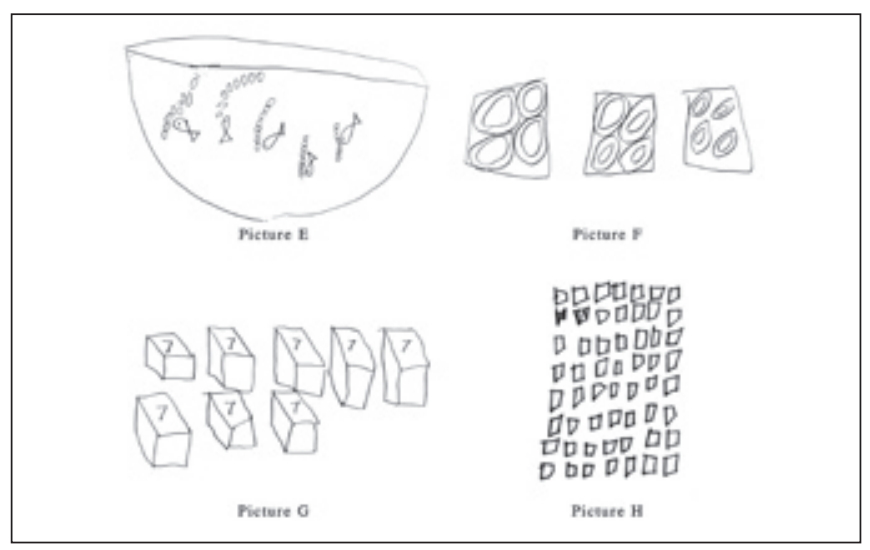

In every case, the pictures by students in the standards-based group showed understanding of multiplication as grouping, and their pictures represented the number of groups, the number in each group, and the product of the multiplication. With few exceptions, the pictures by students in the traditional 
group did not indicate an understanding of multiplication as grouping Instead, their meaning of multiplication was limited to the number sentence and the answer. Those few who wrote word problems about equal groups also created pictures of equal groups.

Writing an addition number sentence. Many students in the traditional group wrote addition number sentences that totaled to the same sum as the product of the multiplication but did not include addends that were related in any way to a multiplication situation. For example, their responses to "Write an addition number sentence that shows $3 \times 4$ " included the following:

- three times four [and] $3 \times 4=12$

- $6+6=12$

- $3+4+1+4=12$

- $3+4=7$

These students' responses indicate that they did not understand enough about how multiplication is different from addition to see how the question was asking for more than the same answer. They knew how to write an addition number sentence, but did not indicate an understanding that both addition and multiplication number sentences can be used to show a number of groups with the same quantity in each group.

In contrast, nearly all of the students in the standards-based group wrote either $4+4+4=12$ or $3+3+3+3=12$ (or both), indicating a clear understanding of the applicability of an addition process to represent a situation involving equal groups. These responses most likely reflected these students' experiences using repeated addition as a strategy for determining answers to multiplication problems. These differences in responses make clear that there can be differences between students' understandings of the structure of a problem and their choices of strategies for solving the problem.

\section{Conclusions}

This study provides evidence that memorizing multiplication facts produced much less understanding of the basic concepts of multiplication in a group of fourth-grade students receiving traditional instruction than a standardsbased curriculum and instruction produced among a group of younger third-grade students. This is consistent with the broader claim that a focus on computational skills alone works against the development of the view that learning mathematics is a sense-making activity (Robinson, Robinson, \& Maceli, 2000). These results also show under what curricular circumstances students have the opportunity to develop robust understandings of basic multiplication concepts, which contrasts with the findings of 0'Brien and Casey (1983a, b) for students experiencing a traditional computation focus. We also found that the collection of tasks described in this article provided meaningful evidence for assessing children's understandings of multiplication concepts, including understandings of the relationships between multiplication and addition. 


\section{References}

Carpenter, T. P., Fennema, E., Franke, M. L., Levi, L., \& Empson, S. B. (1999). Children's mathematics: Cognitively guided instruction. Portsmouth, $\mathrm{NH}$ : Heinemann and Reston, VA: National Council of Teachers of Mathematics. Center for Research in Mathematics and Science Education. (1998).

Reconceptualizing mathematics: Courseware for elementary and middle grade teachers_ number and number sense [CD-ROM]. San Diego, CA: San Diego State University.

Greer, B. (1992). Multiplication and division as models of situations. In D. A. Grouws (Ed.), Handbook of research on mathematics teaching and learning (pp. 276-295). New York: Macmillan.

Harel, G. \& Confrey, J. (Eds.). (1994). The development of multiplicative reasoning in the learning of mathematics. New York: State University of New York Press.

Hiebert, J. \& Behr, M. (Eds.). (1988). Number concepts and operations in the middle grades. Hillsdale, NJ: Erlbaum and Reston, VA: National Council of Teachers of Mathematics.

McIntosh, A. (June 1979). Some children and some multiplications.

Mathematics Teaching.

National Council of Teachers of Mathematics. (2000). Principles and standards for school mathematics. Reston, VA: Author.

0’Brien, T. C., \& Casey, S. A. (1983a). Children learning multiplication: Part I. School Science and Mathematics, 83(1), 246-251.

0’Brien, T. C., \& Casey, S. A. (1983b). Children learning multiplication: Part Two. School Science and Mathematics, 83(5), 407-412.

Robinson, E. E., Robinson, M. F., \& Maceli, J. C. (2000). The impact of standards-based instructional materials in mathematics in the classroom. In M. J. Burke \& F. R. Curcio (Eds.), Learning mathematics for a new century (pp. 112-126). Reston, VA: National Council of Teachers of Mathematics.

Sowder, J., Armstrong, B., Lamon, S., Simon, M., Sowder, L., \& Thompson, A. (1998). Educating teachers to teach multiplicative structures in the middle grades. Journal of Mathematics Teacher Education, 1, 127-155.

Tierney, C., Berle-Carman, M., \& Akers, J. (1998). "Things that come in groups (Grade 3: Multiplication and division)." Investigations in Number, Data, and Space. White Plains, NY: Dale Seymour.

\section{Appendix}

\section{Interview Items}

$1.3 \times 4=$

2. Write a story problem for which $3 \times 4$ is the correct number sentence.

3. Draw a picture that shows $3 \times 4$.

4. Write an addition number sentence that shows $3 \times 4$.

5-8. Repeat 1-4 sequence with $5 \times 8$.

9-12. Repeat 1-4 sequence with $8 \times 7$.

13-16. Repeat $1-4$ sequence with $9 \times 6$.

17. Peter has 6 packets of cards. Each packet contains 7 cards. How many cards does Peter have altogether?

18. Sarah walks 3 miles an hour. How long will it take her to walk 21 miles?

19. Jane has 16 dollars. Hamburgers cost 2 dollars each. How many hamburgers can Jane buy?

20. A giraffe is 3 times as tall as a man is. If the man is 6 feet tall, how tall is the giraffe?

21. Jennifer has some boxes for her toys. There are 9 toys in each box. Altogether there are 54 toys. How many toy boxes does Jennifer have?

22. Bill bought 8 pizzas. Each pizza had the same number of slices. Altogether there are 56 slices. How many slices are there in each pizza?

23. If 3 wolves were running in a pack, how many legs would be in the pack?

24. If 5 octopuses were on a beach, how many octopus arms would there be?

25. How many days are there in eight weeks?

26. If 9 people each bought half a dozen eggs, how many eggs would they buy altogether? 